University of Nebraska - Lincoln

DigitalCommons@University of Nebraska - Lincoln

USDA National Wildlife Research Center - Staff Publications
U.S. Department of Agriculture: Animal and Plant Health Inspection Service

2020

\title{
Piscivorous Bird Use of Aquaculture and Natural Water Bodies in Mississippi
}

Paul C. Burr

Mississippi State University, pcb124@msstate.edu

Jimmy I. Avery

Mississippi State University, jla15@msstate.edu

Garrett M. Street

Mississippi State University, gms246@msstate.edu

Bronson K. Strickland

Mississippi State University, bronson.strickland@msstate.edu

Brian S. Dorr

USDA-APHIS NWRC, brian.s.dorr@aphis.usda.gov

Follow this and additional works at: https://digitalcommons.unl.edu/icwdm_usdanwrc

Part of the Natural Resources and Conservation Commons, Natural Resources Management and Policy Commons, Other Environmental Sciences Commons, Other Veterinary Medicine Commons, Population Biology Commons, Terrestrial and Aquatic Ecology Commons, Veterinary Infectious Diseases Commons, Veterinary Microbiology and Immunobiology Commons, Veterinary Preventive Medicine, Epidemiology, and Public Health Commons, and the Zoology Commons

Burr, Paul C.; Avery, Jimmy I.; Street, Garrett M.; Strickland, Bronson K.; and Dorr, Brian S., "Piscivorous Bird Use of Aquaculture and Natural Water Bodies in Mississippi" (2020). USDA National Wildlife Research Center - Staff Publications. 2376.

https://digitalcommons.unl.edu/icwdm_usdanwrc/2376

This Article is brought to you for free and open access by the U.S. Department of Agriculture: Animal and Plant Health Inspection Service at DigitalCommons@University of Nebraska - Lincoln. It has been accepted for inclusion in USDA National Wildlife Research Center - Staff Publications by an authorized administrator of DigitalCommons@University of Nebraska - Lincoln. 


\title{
Piscivorous Bird Use of Aquaculture and Natural Water Bodies in Mississippi
}

\author{
PAUL C. BURR (D), ${ }^{1}$ Mississippi State University, Department of Wildlife, Fisheries and Aquaculture, Box 9690, Mississippi State, MS 39762, USA \\ JIMMY L. AVERY, Mississippi State University, National Warmwater Aquaculture Center, 127 Experiment Station Road, Stoneville, MS 38776, USA \\ GARRETT M. STREET, Mississippi State University, Department of Wildlife, Fisheries and Aquaculture, Box 9690, Mississippi State, \\ MS 39762, USA \\ BRONSON K. STRICKLAND, Mississippi State University, Department of Wildlife, Fisheries and Aquaculture, Box 9690, Mississippi State, \\ MS 39762, USA \\ BRIAN S. DORR, United States Department of Agriculture, Wildlife Services, National Wildlife Research Center, Box 6099, Mississippi State, \\ MS 39762, USA
}

\begin{abstract}
Double-crested cormorants (Phalacrocorax auritus) and great egrets (Ardea alba) have an extensive history of human-wildlife conflict with the aquaculture industry of western Mississippi, USA, due to their depredation of cultured catfish (Ictalurus spp.). Although aquaculture is abundant, western Mississippi also contains naturally occurring water bodies that offer alternative forage opportunities to these species. How cormorants or egrets distribute themselves among these 2 foraging options is unknown, but it has been generally assumed each species uses aquaculture disproportionately more because of the high density of available prey. To test this assumption, we surveyed these species on aquaculture and naturally occurring water bodies using aerial surveys from October through April of 2015-2016, 2016-2017, and 2017-2018. We modeled the proportion of each species on aquaculture as a function of year, date, and weather-related variables using quasi-binomial generalized linear models. Egrets used aquaculture consistently more than what was proportionally available to them and use was not influenced by any of the variables we measured. Proportional use of aquaculture by cormorants was lowest during October through January but steadily increased through April, indicating a distribution shift toward aquaculture in the months immediately prior to their migration. The highest proportional use of aquaculture by cormorants occurred in 2016, a year when lethal control measures were not allowed against cormorants. Conversely, the least proportion of cormorants on aquaculture was in 2015 when cormorants could be lethally controlled under authority of an Aquaculture Depredation Order. This trend highlights the potential influence of changes in mortality risk, caused by changes in policy regarding lethal take of cormorants, on cormorant distribution between foraging options. (C) 2020 The Wildlife Society.
\end{abstract}

KEY WORDS aquaculture, Ardea alba, catfish, depredation order, double-crested cormorant, forage use, great egret, human-wildlife conflict, Mississippi, Phalacrocorax auritus.

Mississippi, USA, contains approximately $18,000 \mathrm{~km}^{2}$ of the Mississippi Alluvial Valley located in the western portion of the state, regionally known as the Mississippi Delta (i.e., Delta; Fig. 1). The Delta was historically covered by bottomland hardwood forests, marshes, and wetlands, but beginning in the 1800s was steadily cleared and drained for agriculture (McWilliams and Rosson 1990; Stanturf et al. 1998, 2000). Catfish (Ictalurus spp.) aquaculture practices began in the 1960s and thrived in the Delta because of the large quantities of ground water, flat topography, and the presence of clay soils with low infiltration rates (Tucker and Hargreaves 2004, Hanson and Sites 2015). With the loss of wetlands, piscivorous avian

Received: 21 January 2020; Accepted: 15 July 2020

${ }^{1}$ E-mail: pcb124@msstate.edu species that inhabit the Delta have presumably shifted their foraging to the now abundant aquaculture. This foraging behavior has resulted in human-wildlife conflict between avian species and the aquaculture industry through the depredation of cultured catfish (Stickley and Andrews 1989, Glahn et al. 1999, Taylor and Dorr 2003, Glahn and King 2004). Two of the most common species associated with this conflict in the Delta are the double-crested cormorant (Phalacrocorax auritus; cormorant), and great egret (Ardea alba; egret; Wywialowski 1999, Taylor and Dorr 2003).

Cormorants inhabit the Delta primarily from October through April as part of their annual migration from the upper midwestern United States, whereas egrets can be found year-round; although, their numbers are typically higher in spring through fall (McCrimmon et al. 2011, King et al. 2012, Dorr et al. 2014). Because each species has 


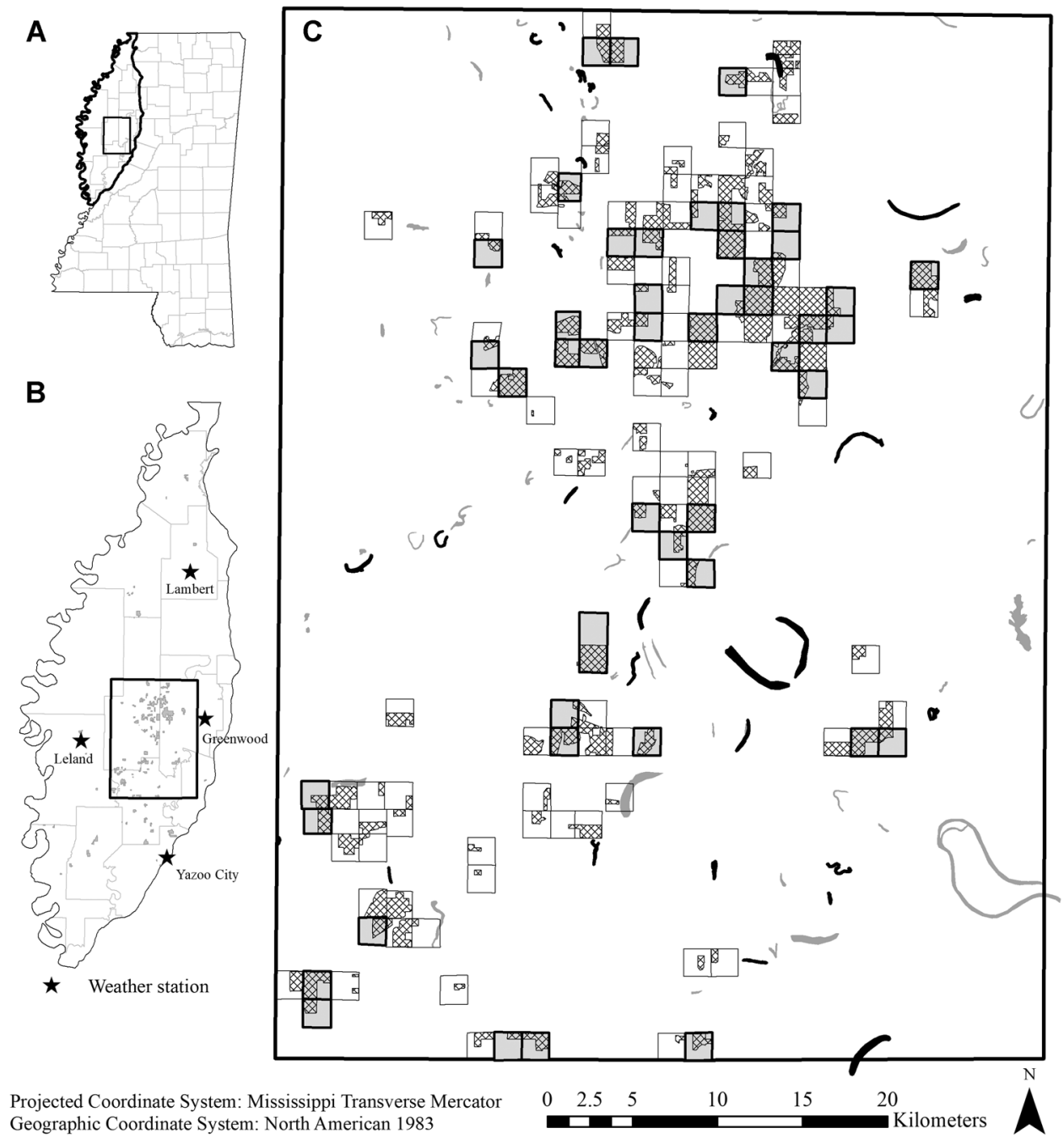

Figure 1. Portion of the Mississippi Alluvial Valley located in Mississippi, USA, known as the Mississippi Delta (A and B). Sample frame established in the Mississippi Delta in which we conducted aerial surveys to estimate the abundance of double-crested cormorants and great egrets on aquaculture ponds and naturally occurring water bodies (C). Cross-hatched shapes represent aquaculture present during the study. Solid black shapes represent the $30 \%$ randomly selected naturally occurring water bodies surveyed, while solid gray shapes represent the remainder. Solid gray boxes outlined with thick black borders represent the 30\% randomly selected aquaculture clusters that were surveyed. We conducted approximately 2 surveys per month from October through April of 2015-2016, 2016-2017, and 2017-2018. Solid black stars represent locations of weather stations used to collect weather-related data during this study (B).

a high affinity for fish, cormorants and egrets regularly use aquaculture facilities throughout the Delta. Both species depredate catfish at aquaculture facilities to varying degrees, but cormorants are considered the industry's primary source of financial loss attributed to piscivorous birds (Mott and Brunson 1995, Glahn and King 2004, Dorr et al. 2012, Feaga et al. 2015). Although the Delta contains a substantial amount of aquaculture, there are also naturally occurring water bodies found throughout the area. Catfish farmers, wildlife managers, and researchers have assumed that cormorants and egrets use aquaculture facilities disproportionately to naturally occurring water bodies because of the high density of food available in aquaculture ponds, but this assumption has not been evaluated.

The aquaculture industry in the Delta provides a rich source of food at high densities, which is readily available to avian predators throughout the year. But the presence of humans and anthropogenic disturbances may elicit avoidance behavior. Additionally, there are many dispersal methods implemented by catfish producers to reduce avian presence, such as pyrotechnics and gun fire (Mott and Boyd 1995, Reinhold and Sloan 1997, Wires et al. 2001). Lethal take of cormorants has traditionally been allowed through the Aquaculture Depredation Order (AQDO; U.S. Fish and Wildlife Service [USFWS] 2014), and producers can apply for permits to lethally take egrets. The AQDO has been controversial and has received attention regarding its usefulness and effects on cormorants (Wires 2016). As a result, the AQDO has undergone changes in recent years. In May 2016, the United States District Court for the District of Columbia vacated the AQDO, ceasing all lethal control methods at aquaculture facilities until an environmental assessment was conducted. In November 2017, the USFWS published an environmental assessment in the Federal Register that allowed aquaculture facilities to apply for permits to lethally control cormorants, although the 
number that could be taken lethally was reduced as compared to what was allowable under the AQDO (USFWS 2017).

Compared to aquaculture facilities, naturally occurring water bodies have fewer human-caused disturbances that would elicit avoidance, particularly disturbances directly focused at cormorants or egrets, such as those previously described. The perceived mortality risk associated with naturally occurring water bodies is likely less than at aquaculture facilities. For instance, aquaculture facilities have full-time personnel devoted to harassment and lethal take of birds when allowed, whereas there are very few documented natural predators of adult cormorants or egrets, and the few occasional predations reported are mainly attributed to large raptors, such as the bald eagle (Haliaeetus leucocephalus; McCrimmon et al. 2011, Dorr et al. 2014). This increased risk of mortality on aquaculture is supported, at least for cormoants, by long-term banding data and modeling of breeding cormorant surveys in the Great Lakes in the United States and Canada, indicating increased cormorant mortality due to control efforts on wintering grounds (Seamans et al. 2012, Stromborg et al. 2012, Guillaumet et al. 2014). Although the risk may be lower on naturally occurring water bodies, the food supply is less dense compared to what is available at aquaculture facilities (Bryant 2010, U.S. Department of Agriculture 2010). The behavior of cormorants and egrets to choose between manmade structures and a more natural setting is likely based on mortality risk and prey abundance and availability.

The objective of this study was to evaluate water body use of cormorants and egrets in the Delta by measuring their distribution at catfish aquaculture facilities and naturally occurring water bodies and comparing these to the availability of each. We hypothesized the fitness benefits of increased forage potential at aquaculture facilities was greater than that of decreased risk in natural settings. In general, we predicted greater proportional use of aquaculture than what is proportionally available relative to naturally occurring water bodies. We hypothesized foraging needs would differ throughout the season based on migration phenology. For example, Glahn et al. (1997) reported cormorants wintering closer to aquaculture had greater increases in body mass prior to migration compared to cormorants remote from catfish production, and hypothesized aquaculture contributed to cormorant fitness. Given this information, we predicted cormorants preparing to migrate north during the latter survey months would seek out foraging habitat with higher food densities to build energy reserves for migration, and therefore show higher use of aquaculture compared to naturally occurring water bodies as opposed to earlier in the fall. Although considered year-round residents, individual egrets do exhibit migratory behavior typically in February (McCrimmon et al. 2011). We therefore predicted to observe similar patterns as cormorants in relation to migration. Lastly, we hypothesized the mortality risk associated with changes in the AQDO (i.e., lethal control measures) would influence cormorant distribution between aquaculture facilities and natural water bodies. Based on perceived risk levels, we predicted the proportion of cormorants on aquaculture would be lowest in 2015, highest in 2016, and intermediate in 2017.

\section{STUDY AREA}

This study was conducted in a 2,772- $\mathrm{km}^{2}$ study area established in the primary catfish producing area of the Delta, mainly in Humphreys, Leflore, and Sunflower counties of Mississippi (Fig. 1B) from mid-fall through early spring. Surveys began in October and ended in April of 2015-2016, 2016-2017, and 2017-2018 (i.e., study years 2015, 2016, 2017). The average temperature in this area, from October through April, was $12.7^{\circ} \mathrm{C}$, and the average rainfall was $80.4 \mathrm{~cm}$ (National Oceanic Atmospheric Administration 2020). The dominant landcover within our sample frame was cultivated crops (72\%), followed by woody wetland $(12 \%)$, and open water, which includes aquaculture and natural water bodies (9\%). During the time of this work the major cultivated crops included soybeans, corn, and cotton. Dominant fauna from surveyed areas included great blue heron (Ardea herodis), American white pelican (Pelecanus erythrorhynchos), waterfowl (Anatidae), North American beaver (Castor canadensis), and muskrat (Ondatra zibethicus). The study area has a flat topography, with an elevation change of approximately $23 \mathrm{~m}$ over the entire area.

To obtain the most current location data of water bodies, we manually digitized all aquaculture and naturally occurring water bodies within the sample frame in a geographic information system (ArcGIS 10.2, Esri, Redlands, CA, USA) using multispectral satellite imagery and high-resolution aerial imagery. The multispectral satellite imagery $(30-\mathrm{m}$ resolution) was taken from the Landsat- 8 satellite on 15 August 2015 and obtained from the United States Geological Survey (USGS) Earth Explorer (https:// earthexplorer.usgs.gov/, accessed 18 Sep 2015). We used a multi-band method combining the Landsat- 8 spectral bands 5,6 , and 4 , and displayed them as red, green, and blue, respectively, to improve surface water detection (Rokni et al. 2014). The high-resolution $(\sim 0.5 \mathrm{~m})$ imagery was taken and mosaicked by the National Agriculture Imagery Program (NAIP) from July to October of 2014 and obtained from the United States Department of Agriculture, Geospatial Gateway (https://datagateway.nrcs.usda.gov, accessed 11 May 2015). We used the Landsat- 8 data to locate all current water bodies, and the NAIP imagery to accurately digitize them. Our sample frame contained $73.5 \%$ of all aquaculture surface area within the entire Delta, totaling approximately $118 \mathrm{~km}^{2}$ of aquaculture, and approximately $22 \mathrm{~km}^{2}$ of naturally occurring water bodies (Fig. 1C). We characterized naturally occurring water bodies as non-flowing, unmanaged water bodies. These were composed mostly of oxbow lakes around riverine areas, bayous, and flooded timber areas. Surface area of each category varied slightly between years because of variation in production and precipitation.

\section{METHODS}

We conducted aerial surveys to estimate the abundance of cormorants and egrets on naturally occurring water bodies and aquaculture ponds within the sample frame. We used a 
simple random sample to select naturally occurring water bodies to survey. Catfish ponds are on average 3.5 ha (U.S. Department of Agriculture 2010), and we disregarded any naturally occurring water bodies that were smaller than 3.5 ha. Cormorants forage on larger areas of water, and therefore are less likely to use smaller natural water bodies (Dorr et al. 2014). Retaining these smaller water bodies would likely bias our results, showing greater use of aquaculture, whereas removing them from selection was a more conservative approach. Only 11 naturally occurring water bodies were smaller than $3.5 \mathrm{ha}$, and 88 were greater, of which $30 \%(n=26)$ were randomly selected for surveys (Fig. 1C). We dropped 3 water bodies from our sample at the end of the 2015 survey season because of low water levels, and randomly selected an additional 3 to survey in 2016 and 2017. We used a cluster sampling method to survey birds on aquaculture clusters (Dorr et al. 2008). We defined aquaculture clusters as all USGS land survey sections that contained catfish ponds. Approximately 131 aquaculture clusters were within our sample frame, but the number of clusters varied between years because of ponds going in and out of production. Of these, we randomly selected $30 \%(n=40)$ to be surveyed each year (Fig. 1C). Our goal was to survey the same clusters each year; however, 6 clusters in 2015 and 1 cluster in 2016 ceased production, so we randomly selected replacement clusters for the following year's survey. We chose a sample of $30 \%$ of clusters for this study to maximize sample size while maintaining the ability to survey the sample within a single day. Dorr et al. (2008) reported this method of cluster sampling to be an acceptable survey method for species that show patchy distributions on aquaculture sites, such as cormorants and egrets.

We flew surveys from October through April, coinciding with cormorant movement through Mississippi (Dorr et al. 2008, Wires 2016). Our goal was to fly 2 surveys per month, with each flight limited to $\leq 8$ hours to ensure counts were completed in 1 day and to avoid double counting. Each survey began 1 hour after sunrise so they could be completed during daylight. We conducted surveys in a fixed-wing aircraft at an altitude of $100-150 \mathrm{~m}$ above ground level. The pilot circled over selected clusters and naturally occurring water bodies while an observer recorded all target species on each water body. Cormorants and egrets did not appear to alter their behavior or flight during surveys; thus, we did not observe movement between water bodies or among clusters during surveys. Dorr et al. (2008) also reported cormorants to typically stop foraging and show alert behavior while the aircraft passes; thus, we did not expect diving behavior in response to the aircraft. We varied survey routes randomly to decrease the probability of surveying locations at the same relative time between surveys. These research methods were approved under United States Department of Agriculture, Wildlife Services, National Wildlife Research Center Quality Assurance protocol QA2322, including Institutional Animal Care and Use and attending vet approvals.

We took digital photographs of cormorants and egrets on a subset of aquaculture ponds and naturally occurring water bodies to correct for error associated with observer counting. We systematically chose ponds and naturally occurring water bodies to be photographed, ensuring that we covered a range of counts. We used linear regression to model picture counts against estimates made while flying, keeping the intercept set to zero (Glahn et al. 2000a). We used the estimated slope from these regression models as a correction factor for all aerial counts. We constructed individual correction factors for each observer, by species and water body type (natural or aquaculture), and adjusted survey counts accordingly.

We constructed our survey count data to fit a binomial distribution where our response variable was the proportion of birds on aquaculture ponds per survey (Zuur et al. 2009). For example, on 9 February 2017 we counted 1,003 cormorants on aquaculture ponds and 135 on natural water bodies, resulting in a survey proportion of 0.88 . This is common practice when analyzing proportional data in which cases are grouped either spatially or temporally (Vicente et al. 2006, Zuur et al. 2009). Moreover, we were interested in determining what variables influence how these birds distribute themselves between water body types, not based on variables related to individual birds themselves, but rather variables associated with the survey, such as date, weather conditions, and year.

We examined the variable of ordinal date (where 1 Oct $=1$ ) to determine if proportional use of aquaculture varied temporally. We also examined how mortality risk (changes in the AQDO) influenced cormorant distribution between water body types using year as a categorical variable. The 2015 survey year represented maximum risk to cormorants because producers could lethally remove cormorants from their farms with no limit. The 2016 survey year represented the lowest risk because the AQDO was ceased and no lethal measures against cormorants were legal. Finally, we viewed the 2017 survey year as an intermediate risk level because producers were able to apply for permits to lethally remove cormorants, but only a limited number could be taken from their facilities. Because egrets were not directly affected by changes in the AQDO, we made no predictions regarding differences in proportional use of aquaculture among years for egrets; however, we still included year when modeling egrets to account for potential variation.

We were also interested in the possible influence of either temperature or precipitation on proportional use of foraging options. Water levels in naturally occurring water bodies are sensitive to precipitation, whereas aquaculture pond depths are controlled, and temperature can contribute to diet variability of cormorants (Dorr et al. 2014). To calculate these variables, we first collected daily precipitation and maximum temperature values over the duration of our study from 4 weather stations spaced around our survey area (Fig. 1B). These weather stations were located in the cities of Yazoo City, Leland, Lambert, and Greenwood. We obtained weather data from the National Centers for Environmental Information through the National Oceanic and Atmospheric Administration website (https://www.ncdc. noaa.gov/, accessed 18 Jun 2018). We averaged these values 
on a daily basis to obtain a daily temperature and precipitation value representative of the region. For each survey we averaged the maximum temperature over 7 days, including the survey day and the 6 days prior. Similarly, we calculated the precipitation variable as the accumulation of rainfall within the same period. Our goal was to develop a measurement of these weather variables over a time representing ongoing conditions experienced by these species prior to each survey. We chose 7 days as an intermediate between the minimum of 1 day (survey day) and the maximum 14 days between surveys. Our hope was also to decrease correlation in values between consecutive surveys.

We conducted all analyses using Program R (version 3.5.1, www.r-project.org, accessed 9 Mar 2018). We modeled ordinal date up to a third-order polynomial because we predicted aquaculture use would be dynamic over the survey season. We also modeled temperature and precipitation up to quadratic terms to allow for possible non-linear relationships. We checked for collinearity among predictor variables using variance inflation factors (VIF) calculated from the full model. We used the cut off of VIF $>5$ to determine if a variable should be removed (Zuur et al. 2009). We constructed a global model for cormorants and egrets separately, and started our analysis using a binomial generalized linear model (GLM). Each global model included the categorical variable of year, ordinal date up to a third-order polynomial, and precipitation and temperature both up to a second-order polynomial. Because our data was grouped by survey, overdispersion must be checked for in this framework (McCullagh and Nelder 1989). We detected overdispersion in global models for both species and therefore continued using a quasi-binomial GLM to correct standard errors (Zuur et al. 2009). This quasi-binomial method does not allow for the use of Akaike's Information Criterion (AIC) procedures, so we conducted variable selection using the drop1 function in R (Zuur et al. 2009). This function drops each individual term from the model and calculates the resulting model deviance given each variable's removal. Because we used the quasi-binomial method, we scaled the resulting difference in deviance by dividing the deviance difference by the estimated dispersion parameter. The deviance estimate follows an $F$ distribution, which provides a measure of variable importance, providing an $F$-statistic and associated $P$-value. The variable associated with the largest $P$-value $>0.05$ is removed first and the resulting model is evaluated again using the drop1 function. We repeated this process until all remaining variables had a $P$-value $<0.05$. We further validated the final model by examining deviance residuals plotted against the predicted response values and independent variables to ensure that patterns indicated no violations of model assumptions (Zuur et al. 2009).

We used the package effects in Program $\mathrm{R}$ to calculate means and confidence intervals, and to graphically display the influence of independent variables on proportional use of aquaculture (Fox and Hong 2009). For the categorical variable of year, we performed post hoc pairwise comparisons to test for differences between survey years using a Tukey correction in package emmeans (Lenth 2019). We made inferences from model estimates for cormorants by comparing them to the proportion of aquaculture available by surface area. On average, we sampled 3,273 ha of aquaculture, and 646 ha of naturally occurring water bodies each year, resulting in a proportion of water surface area of 0.83 as aquaculture, and 0.17 as natural. In effect, if no preference of water body type exists, we would expect modeled estimated proportions of cormorants on aquaculture to be approximately 0.83 . Cormorants forage in open water, and therefore have access to the entire area of either aquaculture ponds or naturally occurring water bodies. Egrets, however, are restricted to shallower waters, typically $<0.5 \mathrm{~m}$ deep (McCrimmon et al. 2011). We therefore compared modeled proportion of egrets on aquaculture by perimeter. On average, we sampled $755 \mathrm{~km}$ of aquaculture, and $99 \mathrm{~km}$ of natural water bodies each year, resulting in a proportion based on perimeter of 0.88 as aquaculture and 0.12 as natural.

\section{RESULTS}

We completed 12 surveys in 2015, 12 in 2016, and 9 in 2017. The correction factor estimated from modeling picture counts against aerial counts on aquaculture and naturally occurring water bodies averaged $1.01(n=136)$ and $0.97(n=27)$ for cormorants, and $0.88(n=74)$ and 0.90 $(n=11)$ for egrets, respectively. Total adjusted cormorant counts for all surveys combined were 24,735 on aquaculture and 7,961 on naturally occurring water bodies. Total adjusted counts for egrets were 14,913 on aquaculture and 837 on naturally occurring water bodies. In general, counts were consistent among years for both species (Fig. 2). Cormorant abundance showed a slight peak early in the survey season (Nov-Dec), followed by a larger peak from February through March. Egret abundance was greatest early in the survey season (Oct), then gradually decreased through April (Fig. 2).

There was no evidence of collinearity among any predictor variables in the global models (VIFs $<5$ ), so we retained all variables during model construction. The variable selection process for cormorants retained the variables year, the linear term of precipitation, and the quadratic term of ordinal date (Table 1). Proportion of cormorants on aquaculture by ordinal date showed an increase throughout the survey season, with the lowest values occurring from October through January followed by an increase through April of each year (Fig. 3). The proportion of cormorants on aquaculture was lowest in 2015, averaging 0.52 (range $=0.34-0.91$ ) over the survey season (Fig. 3). The 2015 estimates and 95\% confidence intervals were below the proportion of aquaculture available by surface area (0.83) for most of survey season. The proportion of cormorants on aquaculture in 2016 was greater than $2015 \quad(P<0.001)$, averaging 0.85 (range $=0.77-0.98$ ) over the survey season. Estimates and 95\% confidence intervals over the entire 2016 season contained, or were above, the 0.83 threshold (Fig. 3). Finally, the proportion of cormorants on aquaculture in 2017 was greater than $2015(P=0.009)$ but only trended less than 


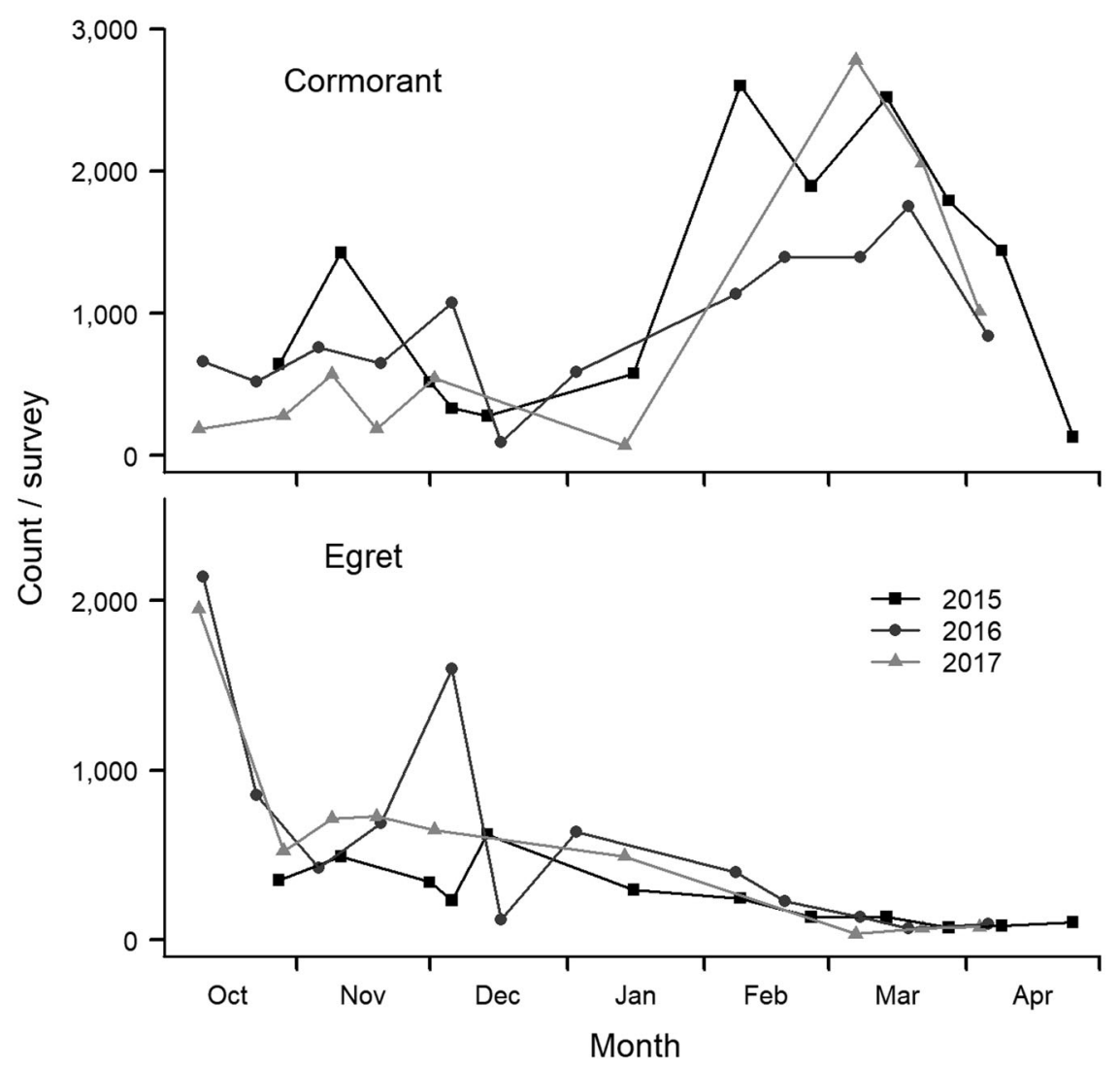

Figure 2. Abundance of double-crested cormorants and great egrets counted during aerial surveys of aquaculture ponds and naturally occurring water bodies in the Mississippi Delta, USA. We conducted approximately 2 surveys per month from October through April of 2015-2016, 2016-2017, and 2017-2018.

$2016(P=0.214)$, averaging 0.75 (range $=0.62-0.97)$ over the survey season. In 2017 the estimates and 95\% confidence intervals fell below 0.83 for part of the survey season, primarily in November and December, but otherwise contained or were above 0.83 (Fig. 3). Lastly, precipitation values ranged from 0 to $23 \mathrm{~cm}$ within our survey samples. Precipitation had a positive effect on cormorants'

Table 1. Results of quasi-binomial generalized linear models of the proportion of double-crested cormorants and great egrets found on aquaculture in the Mississippi Delta, USA. Variable estimates, along with standard error (SE), 95\% lower (LCI) and upper (UCI) confidence intervals, and $P$-values are shown. We collected data from October through April of 2015-2016, 2016-2017, and 2017-2018, with 2015-2016 modeled as the reference group.

\begin{tabular}{lrrrrr}
\hline Coefficients & Estimate & SE & 95\% LCI & 95\% UCI & \multicolumn{1}{c}{$\boldsymbol{P}$} \\
\hline Cormorant & & & & & \\
Intercept & -0.156 & 0.257 & -0.662 & 0.349 & 0.547 \\
Year (2016-2017) & 1.868 & 0.373 & 1.162 & 2.632 & $<0.001$ \\
Year (2017-2018) & 1.130 & 0.387 & 0.387 & 1.916 & 0.007 \\
Date $^{\mathrm{a}}$ & 4.437 & 0.944 & 2.611 & 6.328 & $<0.001$ \\
Date $^{2}$ & 2.352 & 1.040 & 0.364 & 4.461 & 0.032 \\
$\quad$ Precipitation $^{\mathrm{b}}$ & 0.098 & 0.035 & 0.035 & 0.174 & 0.009 \\
Egret $^{\text {Intercept }}$ & & & & & \\
\hline
\end{tabular}

${ }^{\text {a }}$ Ordinal date, where 1 October is set as 1 .

b Total rainfall accumulated on the survey day and 6 days prior to $(\mathrm{cm})$. proportional use of aquaculture, with greater proportions occurring during wetter conditions (Fig. 4).

The variable selection process for egrets retained no variables, indicating a constant proportion of egrets on aquaculture regardless of temporal or weather-related conditions (Table 1). The proportion of egrets on aquaculture was 0.95 $(95 \% \mathrm{CI}=0.92-0.97)$, which was above the proportion of aquaculture available by perimeter (0.88).

\section{DISCUSSION}

We tested the assumption that cormorants and egrets use aquaculture disproportionally more to what is available and found it to be supported to varying degrees. Proportion of cormorants on aquaculture versus naturally occurring water bodies was highest in 2016 and lowest in 2015 (Fig. 3). During the 2015 survey period catfish producers were allowed to use lethal control against cormorants without a federal permit under the AQDO, and our proportional estimate and confidence intervals of cormorants on aquaculture were lower than what proportionally available for most of the year. During the 2016 survey, the AQDO was ceased and no lethal control methods could be legally used at aquaculture facilities. Other non-lethal means of harassment such as pyrotechnics or the use of live ammunition to scare birds was still an allowable technique used to reduce bird presence (Mott and Boyd 1995, Glahn et al. 2000b). Our proportional estimates of cormorants on aquaculture in 


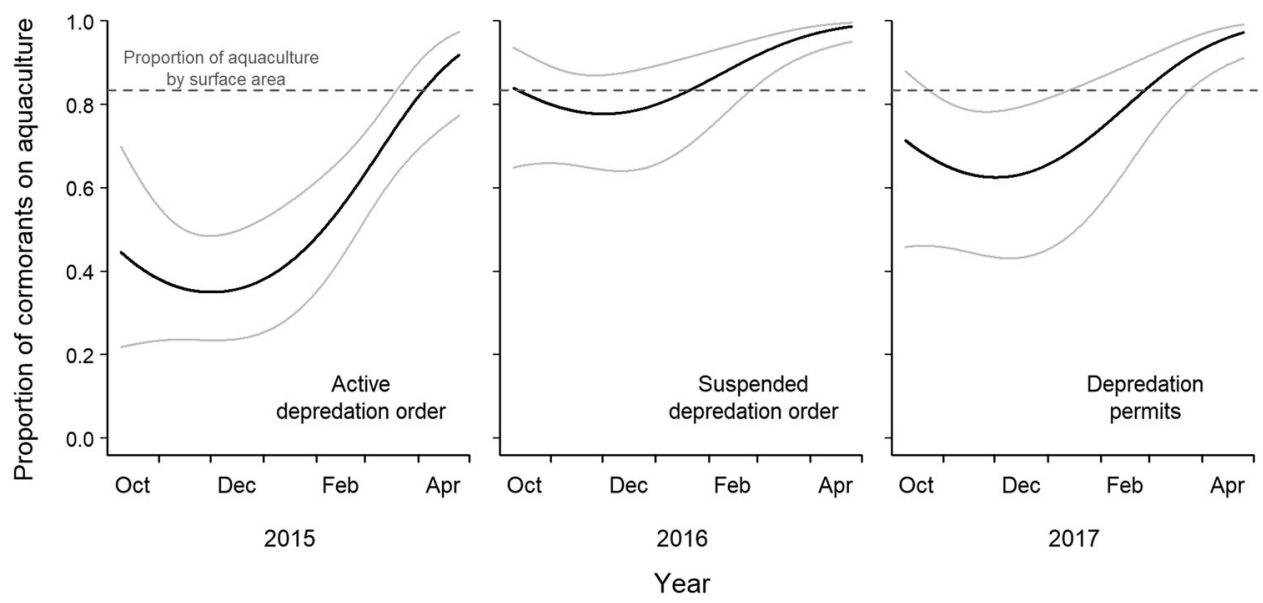

Figure 3. Proportion of double-crested cormorants on aquaculture from October through April of 2015-2016, 2016-2017, and 2017-2018 in the Mississippi Delta, USA. We calculated estimates (solid black line) and $95 \%$ confidence intervals (solid grey line) from a quasi-binomial generalized linear model. The dashed line represents the proportion of surveyed water area classified as aquaculture (0.83). If cormorants were using aquaculture proportional to its availability estimates would fall on the dashed line, whereas estimates above the line indicate higher proportional use of aquaculture.

2016 were equal to or greater than what was proportionally available over the entire survey season. During the 2017 survey year, producers were allowed to once again use lethal measures but were required to apply for a permit and were limited on the number of cormorants taken. Average proportion of cormorants on aquaculture during 2017 was intermediate compared to the previous 2 years but fell below the proportion of aquaculture available by surface for part of the survey season. These findings match our initial predications of lethal control influencing how cormorants

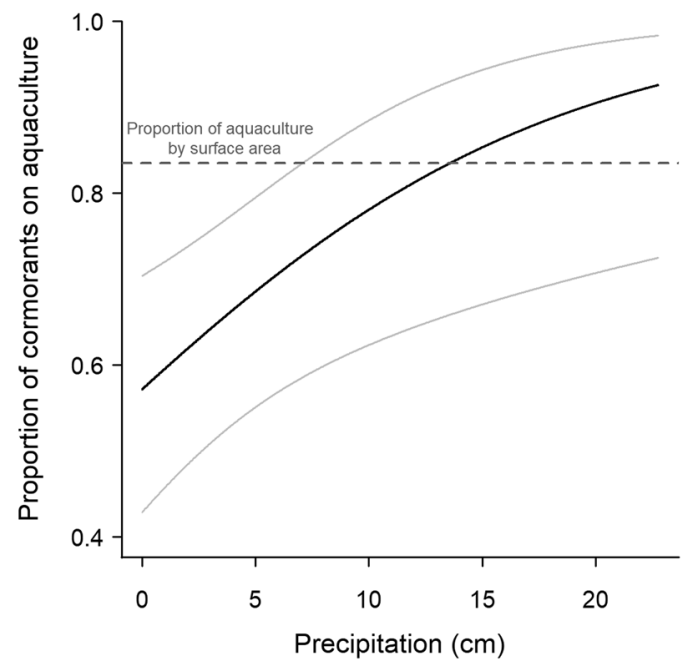

Figure 4. Proportion of double-crested cormorants on aquaculture in a sample frame established in the Mississippi Delta, USA, in relation to precipitation. We calculated estimates (solid black line) and 95\% confidence intervals (solid grey line) from a quasi-binomial generalized linear model with data collected from October through April of 2015-2016, 2016-2017, and 2017-2018. The dashed line represents the proportion of surveyed water area classified as aquaculture (0.83). If cormorants were using aquaculture proportional to its availability, estimates would fall on the dashed line, whereas estimates above the line indicate higher proportional use of aquaculture. distribute themselves between aquaculture and natural water bodies.

Although the ability of producers to successfully kill cormorants has proven to be rather difficult (Hess 1994), removing the mortality risk may result in cormorant habituation to non-lethal methods. Glahn et al. (2000b) reports shooting a limited number of cormorants reinforces other non-lethal harassment, thereby preventing habituation. Similarly, Hess (1994) observed fewer cormorants entering treatment areas where lethal control was being practiced in parts of the Delta. More recently, Hedge and Kumar (2019) presented a case study examining the effectiveness of non-lethal harassment in preventing fish loss and reported that catfish survival in ponds where non-lethal harassment was taking place had $42 \%$ lower survival than ponds not affected by birds at all, resulting in an economic loss of $\$ 8,692$ to $\$ 10,032$ per hectare.

Empirical studies are lacking on the effectiveness of lethal control at aquaculture facilities on reducing cormorant abundance and depredation of fish on ponds, specifically at spatiotemporal scales large enough for robust inference. An ideal study design would require a combination of treatments including no harassment, non-lethal harassment, and lethal control at regional scales, ideally over multiple years. Conducting such a study would be logistically difficult because it would require cooperation from many catfish farmers to reliably continue with treatments, including the willingness to refrain from using methods that would reduce catfish loss. In our case the unforeseen removal of the AQDO provided a unique opportunity to examine such affects, albeit in a correlative manner. Although we cannot be certain that no lethal measures were being taken during 2016, it is reasonable to assume such measures were less than in other years when the AQDO was active (2015) or when permits were being issued (2017).

The absence of lethal measures is just 1 possible reason why we observed the difference among years for cormorants, 
but some arguments lend support to our findings that lethal control measures likely influence cormorant distribution between aquaculture ponds and naturally occurring water bodies. First, there is evidence that lethal take to protect aquaculture resources affects mortality estimates for cormorants at scales as large as the Great Lakes region (Seamans et al. 2012, Stromborg et al. 2012, Guillaumet et al. 2014). The upper Midwest population of cormorants is a primary contributor to birds wintering in the Delta region. Second, our results indicate higher proportion of cormorants on aquaculture during wetter conditions. Given this relationship, we would predict overall higher proportions during wetter years and lower proportions during dryer years, yet the opposite was observed. The highest proportion was in the 2016 season, which averaged $10.3 \pm 4.4(\mathrm{SD}) \mathrm{cm}$ of precipitation per month, whereas the lowest estimated proportion was in 2015, which averaged $17.2 \pm 8.5 \mathrm{~cm} /$ month. In the 2017 survey season, the precipitation was intermediate of the other seasons, averaging $14.8 \pm 11.8 \mathrm{~cm}$ of precipitation per month. Third, the United States Department of Agriculture's (USDA) Wildlife Services began a regional cormorant roost harassment program in 1993 (Taylor and Strickland 2008). Roost harassment is one of the most effective ways of reducing the effects of cormorants on aquaculture (Reinhold and Sloan 1997, Glahn et al. 2000b). This technique typically involves using pyrotechnics, or other frightening devices and tactics, to push cormorants out of roosts and away from areas of aquaculture. Wildlife Services ceased major involvement in the roost harassment program in 2010, but resumed harassment in 2015 (D. D. Lunsford, USDA Wildlife Services, personal communication). During 2015, Wildlife Services had reduced effort in harassing roosts, completing only 22 roost harassments at 9 unique roosts from October through April. But during 2016 and 2017, their roost harassment efforts increased substantially, completing 117 and 90 harassments at 40 and 62 unique roosts, respectively (D. D. Lunsford, personal communication). Given the reduced roost harassment effort in 2015, we would expect to observe a higher proportion of cormorants on aquaculture, yet we observed the opposite. Finally, any stochastic environmental factors substantial enough to influence annual cormorant distribution would likely influence egrets, but we observed no such effect.

Proportion of cormorants on aquaculture varied by date, with the highest values occurring at the end of each survey season. Using bioenergetics models of cormorants, Glahn and Brugger (1995) estimated the number of consumed catfish to be the highest at the end of the winter season when cormorant diet shifted more toward catfish. Our results complement their findings; we observed cormorants shifting their distribution away from naturally occurring water bodies and toward aquaculture later in the survey season (Fig. 3). This shift occurs during the months directly before cormorants begin their migration north (Dorr et al. 2014), suggesting cormorants prepare for the energetically demanding task of migration by focusing more on the abundant and readily available food resources found at aquaculture facilities. The work by Glahn et al. (1997) supports this idea; they reported cormorants found in areas of high aquaculture production had higher omental fat compared to cormorants found away from aquaculture production, which can indicate improved body condition and overall fitness. Although the proportion of cormorants on aquaculture is lower at the beginning of the season, it is probable they still regularly use aquaculture ponds, but the frequency and duration at which they do so likely increases toward the end of their stay in the Delta. At that time the potential forage benefits to migration may outweigh the risks associated with spending time on aquaculture facilities. Precipitation remained in the final cormorant model, revealing a distribution shift more toward aquaculture during wetter periods. Naturally occurring water bodies are susceptible to changes in water level by precipitation, whereas aquaculture ponds are maintained at specific levels regardless of precipitation amount. Changes in water level at naturally occurring water bodies may reduce cormorant foraging efficiency, encouraging more cormorants to use aquaculture. For example, as water levels increase, the density of prey will reduce in naturally occurring water bodies, whereas the density in aquaculture ponds will remain constant. Additionally, during periods with large amounts of rainfall, pond levees can become difficult, if not impossible, to drive on, reducing the efficiency of bird harassment at facilities.

Although proportional use of aquaculture varied for cormorants, egret use showed no variation with any variables measured in this study. These results suggest egrets prefer to use aquaculture compared to naturally occurring water bodies regardless of weather conditions or season. Egrets are commonly viewed as a minimal risk to catfish producers (Wywialowski 1999), and financial loss attributed to them is much lower than cormorants (Glahn and King 2004). In fact, Glahn et al. (1999) reported egret diets in the Delta comprised only $28.3 \%$ catfish by weight, and most catfish consumed were already dead. Therefore, it is likely that less effort goes into the direct harassment of egrets at aquaculture facilities and why the estimated proportions on aquaculture were consistently greater than expected given its availability. Given their high proportional use of aquaculture and their limited consumption of catfish compared to cormorants, egrets may be using aquaculture ponds more as loafing areas or to consume other items such as invertebrates, amphibians, or reptiles (McCrimmon et al. 2011).

It is important to clarify that the estimates reported in this study are simply the proportion of all cormorants or egrets to be on aquaculture within our sample frame compared to naturally occurring water bodies. These do not provide a measurable effect on the catfish industry of Mississippi because total population estimates are not incorporated.

\section{MANAGEMENT IMPLICATIONS}

This study offers insight into the distribution of cormorants and egrets between natural water bodies and man-made aquaculture within the Delta. Our findings can be used to inform management strategies and policy regarding bird use of aquaculture facilities. Our results suggest cormorants use 
aquaculture disproportionately relative to naturally occurring water bodies, particularly prior to spring migration. Therefore, efforts and resources geared toward dispersing cormorants from aquaculture would be best spent in later months. We also found cormorant use of aquaculture relative to natural water bodies was greatest during the year when the AQDO was suspended and least when it was active, suggesting lethal measures provided by the AQDO were an effective means of altering cormorant distribution, thereby reducing damage at aquaculture facilities.

\section{ACKNOWLEDGMENTS}

The findings and conclusions in this publication are those of the authors and should not be construed to represent any official United States Government determination or policy. We thank T. W. Christie, D. D. Lunsford, and D. R. Middleton for their assistance with data collection and field work. We thank S. Clark, P. Kranser, and the late J. E. Risher for their involvement with aerial surveys. We also thank the Mississippi catfish producers who were part of this research for their cooperation during our surveys. This research was funded by the United States Department of Agriculture, Animal and Plant Health Inspection Service, Wildlife Services, National Wildlife Research Center, Cooperative Service Agreements: 14-7428-1045(CA), 157428-1141(CA), 16-7428-1247(CA), 17-7428-1247(CA), and $18-7428-1247(\mathrm{CA})$.

\section{LITERATURE CITED}

Bryant, M. D. 2010. Past and present aquacutic habitats and fish populations of the Yazoo-Mississippi Delta. General Technical Report SRS-130. U.S. Department of Agriculture Forest Service, Southern Research Station, Ashville, North Carolina, USA.

Dorr, B. S., L. W. Burger, and S. C. Barras. 2008. Evaluation of aerial cluster sampling of double-crested cormorants on aquaculture ponds in Mississippi. Journal of Wildlife Management 72:1634-1640.

Dorr, B. S., L. W. Burger, S. C. Barras, and K. C. Godwin. 2012. Economic impact of double-crested cormorant, Phalacrocorax auritus, depredation on channel catfish, Ictalurus punctatus, aquaculture in Mississippi, USA. Journal of the World Aquaculture Society 43:502-513.

Dorr, B. S., J. J. Hatch, and D. V. C. Weseloh. 2014. Double-crested cormorant (Phalacrocorax auritus), version 2.0. Account 441 in A. F. Poole, editor. The birds of North America online. Cornell Lab of Ornithology, Ithaca, New York, USA.

Feaga, J. S., F. J. Vilella, R. M. Kaminski, and B. J. Davis. 2015. Waterbird use of catfish ponds and migratory bird habitat initiative wetlands in Mississippi. Waterbirds 38:269-281.

Fox, J., and J. Hong. 2009. Effect displays in R for multinomial and proportional-odds logit models: extensions to the effects package. Journal of Statistical Software 32:1-24.

Glahn, J., and D. T. King. 2004. Bird depredation. Pages 634-657 in C. S. Tucker and J. Hargreaves, editors. Biology and culture of channel catfish. Volume 34. Elsevier, Amersterdam, The Netherlands.

Glahn, J., D. S. Reinhold, and C. A. Sloan. 2000a. Recent population trends of double-crested cormorants wintering in the Delta region of Mississippi: responses to roost dispersal and removal under a recent depredation order. Waterbirds 23:38-44.

Glahn, J., M. E. Tobin, and B. F. Blackwell. 2000b. A science-based initiative to manage double-crested cormorant damage to southern aquaculture. USDA Animal and Plant Health Inspection Service, Wildlife Services National Wildlife Research Center, Fort Collins, Colorado, USA.

Glahn, J. F., and K. E. Brugger. 1995. The impact of double-crested cormorant on the Mississippi Delta catfish industry: a bioenergetics model. Colonial Waterbirds 18:168-175.
Glahn, J. F., D. S. Reinhold, and P. Smith. 1999. Wading bird depredations on channel catfish Ictalurus punctatus in northwest Mississippi. Journal of the World Aquaculture Society 30:107-114.

Glahn, J. F., M. E. Tobin, and J. B. Harrel. 1997. Possible effects of catfish exploitation on overwinter body condition of double-crested cormorants. Pages 107-113 in M. E. Tobin, technical coordinator. Symposium on double-crested cormorants: population status and management issues in the Midwest. USDA, Animal and Plant Health Inspection Service, Washington, D.C., USA.

Guillaumet, A., B. S. Dorr, G. Wang, and T. Doyle. 2014. The cumulative effects of management on the population dynamics of the double-crested cormorant Phalacrocorax auritus in the Great Lakes. Ibis $156: 141-152$.

Hanson, T., and D. Sites. 2015. 2014 Catfish database. Fisheries and Allied Aquaculture Department Series No. 1. Alabama Agricultural Experiment Station, Auburn, USA.

Hedge, S., and G. Kumar. 2019. Economics of bird depredation: a catfish case study. Thad Cochran National Warmwater Aquaculture Center, NWAC NEWS 16:6-7.

Hess, K. D. 1994. Effectiveness of shooting double-crested cormorants on catfish ponds and harassment of roosts to protect farm-raised catfish. Thesis, Mississippi State University, Mississippi State, USA.

King, T., B. K. Strickland, and A. Radomski. 2012. Migration patterns of double-crested cormorants wintering in the southeastern United States. Waterbirds 35:132-137.

Lenth, R. 2019. emmeans: estimated marginal means, (least-squares means). $\mathrm{R}$ package version 1.2.3. <https://cran.r-project.org/web/ packages/emmeans/>. Accessed 23 Apr 2018.

McCrimmon, D., J. C. Ogden, and G. T. Bancroft. 2011. Great egret (Ardea alba), version 2.0. Account 570 in A. F. Poole, editor. The birds of North America online. Cornell Lab of Ornithology, Ithaca, New York, USA.

McCullagh, P., and J. A. Nelder. 1989. Generalized linear models. Second edition. Chapman and Hall, London, England.

McWilliams, W. H., and J. F. Rosson, Jr. 1990. Composition and vulnerability of bottomland hardwood forests of the coastal plain province in the south central United States. Forest Ecology and Management 33/34:485-501.

Mott, D., and M. Brunson. 1995. A historical perspective of catfish production in the southeast in relation to avian predation. Eastern Wildlife Damage Management Conference 7:23-30.

Mott, D. F., and F. L. Boyd. 1995. A review of techniques for preventing cormorant depredations at aquaculture facilities in the southeastern United States. Colonial Waterbirds 18:176-180.

National Oceanic Atmospheric Administration. 2020. National centers for environmental information, climate at a glance: divisional mapping. $<$ https://www.ncdc.noaa.gov/cag/>. Accessed 19 Jun 2020.

Reinhold, D. S., and C. A. Sloan. 1997. Strategies to reduce doublecrested cormorant depredation at aquaculture facilities in Mississippi. Pages 99-105 in M. E. Tobin, technical coordinator. Symposium on double-crested cormorants: population status and management issues in the Midwest. USDA, Animal and Plant Health Inspection Service, Washington, D.C., USA.

Rokni, K., A. Ahmad, A. Selamat, and S. Hazini. 2014. Water feature extraction and change detection using multitemporal Landsat imagery. Remote Sensing 6:4173-4189.

Seamans, M. E., J. P. Ludwig, K. Stromborg, F. E. Ludwig II, and F. E. Ludwig. 2012. Annual survival of double-crested cormorants from the Great Lakes, 1979-2006. Waterbirds 35:23-30.

Stanturf, J. A., E. S. Gardiner, P. B. Hamel, M. S. Devall, T. D. Leininger, and M. E. Warren. 2000. Restoring bottomland hardwood ecosystems in the lower Mississippi Alluvial Valley. Journal of Forestry 98:10-16.

Stanturf, J. A., C. J. Schweitzer, and E. S. Gardiner. 1998. Afforestation of marginal agricultural land in the lower Mississippi River Alluvial Valley, U.S.A. Silva Fennica 32:281-297.

Stickley, A. R., and K. J. Andrews. 1989. Survey of Mississippi catfish farmers on means, effort, and costs to repel fish-eating birds from ponds. Eastern Wildlife Damage Control Conference 4:105-109.

Stromborg, K. L., J. S. Ivan, J. K. Netto, and C. R. Courtney. 2012. Survivorship and mortality patterns of double-crested cormorants at Spider Island, Wisconsin, 1988-2006. Waterbirds 35:31-39. 
Taylor, J. D., and B. S. Dorr. 2003. Double-crested cormorant impacts to commercial and natural resources. Proceedings of the 10th Wildlife Damage Management Conference 10:43-51.

Taylor, J. D., and B. Strickland. 2008. Effects of roost shooting on doublecrested cormorant use of catfish ponds-preliminary results. Proceedings of the Vertebrate Pest Conference 23:98-102.

Tucker, C., and J. Hargreaves. 2004. Biology and culture of channel catfish. Elsevier, Amersterdam, The Netherlands.

U.S. Department of Agriculture. 2010. Catfish 2010 Part I: reference of catfish health and production practices in the United States, 2009. USDA-APHIS-VS-CEAH-NAHMS, Fort Collins, Colorado, USA.

U.S. Fish and Wildlife Service [USFWS]. 2014. Final environmental assessment. management of double-crested cormorant under $50 \mathrm{cfr} 21.47$ and 21.48. USFWS, Division of Migratory Bird Management, Arlington, Virginia, USA.

U.S. Fish and Wildlife Service [USFWS]. 2017. Environmental assessment for issuing depredation permits for double-crested cormorant management. Division of Migratory Bird Management, Arlington, Virginia, USA.
Vicente, J., U. Hofle, J. M. Garrido, I. G. Fernandez-De-Mera, R. Juste, M. Barral, and C. Gortazar. 2006. Wild boar and red deer display high prevalences of tuberculosis-like lesions in Spain. Veterinary Research 37:107-119.

Wires, L. R. 2016. Migratory bird protection, a crack in the armor: the case of the double-crested cormorant. Avian Conservation and Ecology 10:1-6.

Wires, L. R., F. J. Cuthbert, D. R. Trexel, and A. R. Joshi. 2001. Status of the double-crested cormorant (Phalacrocorax auritus) in North America. Final Report to USFWS, Washington, D.C., USA.

Wywialowski, A. P. 1999. Wildlife-caused losses for producers of channel catfish Ictalurus punctatus in 1996. Journal of the World Aquaculture Society 30:461-472.

Zuur, A. F., E. N. Ieno, N. J. Walker, A. A. Saveliev, and G. M. Smith. 2009. Mixed effects models and extensions in ecology with R. Springer Science \& Business Media, New York, New York, USA.

Associate Editor: Jacob Straub. 